\title{
Level of Fasting C-Peptide as a Predictor of $\beta$-Cell Function in Sudanese Patients with Type 2 Diabetes Mellitus
}

\author{
Hani Yousif Zaki*, Ahmed Abbi Abdille, Badreldin Elsonni Abdalla \\ Department of Biochemistry and Nutrition, Faculty of Medicine, University of Gezira, Wad Medani, Sudan \\ Email: ^hazaki29@hotmail.com
}

How to cite this paper: Zaki, H.Y., Abdille, A.A. and Abdalla, B.E. (2019) Level of Fasting C-Peptide as a Predictor of $\beta$-Cell Function in Sudanese Patients with Type 2 Diabetes Mellitus. Journal of Biosciences and Medicines, 7, 115-123.

https://doi.org/10.4236/jbm.2019.71010

Received: November 25, 2018

Accepted: January 22, 2019

Published: January 25, 2019

Copyright ( 2019 by author(s) and Scientific Research Publishing Inc. This work is licensed under the Creative Commons Attribution International License (CC BY 4.0).

http://creativecommons.org/licenses/by/4.0/

\begin{abstract}
Objective: In this study, we assessed the level of fasting C-peptide as a predictor of $\beta$-cell function and insulin resistance in patients with Type 2 diabetes mellitus (T2DM), Gezira State-Sudan. Methods: In this cross-sectional study, 100 T2DM patients attending the Diabetic patients care Centre were recruited, thirty five patients were males and sixty five were females, the mean age of the patients was $50.29 \pm 0.456$ years, and body mass index (BMI) was $26.54 \pm 0.437$. We estimated $\beta$-cell function using fasting $\mathrm{C}$-peptide levels; homeostatic model assessment for $\beta$-cell function (HOMA-B) and insulin resistance (HOMA-IR) were calculated from C-peptide and fasting blood glucose (FBG). Results: C-peptide was significantly and positively correlated with HOMA-B and HOMA-IR. FBG also showed significant negative correlation with HOMA-B, but was positively and significantly correlated with HOMA-IR. HbA1c was negatively and significantly correlated with HOMA-B. Patients with low C-peptide levels had increased FBG and HbAlc level, while patients with high $\mathrm{C}$-peptide levels were having high HOMA-IR and HOMA-B. Conclusions: Fasting C-peptide is a useful marker of pancreatic $\beta$-cell function, and its circulating levels could be used to evaluate insulin secretion and insulin resistance. Moreover, HOMA-IR is an effective index to achieve glycemic control by appropriate pharmacologic treatment of T2DM.
\end{abstract}

\section{Keywords}

$\beta$-Cell Function, C-Peptide, Insulin Resistance, Type 2 Diabetes Mellitus

\section{Introduction}

Diabetes is a class of diseases where an individual cannot properly maintain 
plasma glucose levels; it is categorized by eminent blood glucose concentrations secondary to either resistance to the action of insulin, inadequate insulin secretion, or both [1]. The International Diabetes Federation (IDF) statistics on the global prevalence of diabetes suggests that, in 2015, 415 million people had diabetes worldwide, projecting that in 2040 this number will increase to 642 million [2]. Diabetes mellitus is the ninth major cause of death and about 1 in 11 adults worldwide now have diabetes mellitus, $90 \%$ of them have type 2 diabetes mellitus (T2DM) [3]. T2DM is influenced by lifestyle factors, such as age, pregnancy, and obesity, but has a strong genetic component [4]; it encompasses persons who have insulin resistance and usually have relative (rather than absolute) insulin deficiency. At least initially, and often during their lifetime, these individuals do not require insulin treatment to survive [5]. In response to high levels of blood glucose within the $\beta$-cells of the pancreatic islets of langerhans, preproinsulin is formed in the endoplasmic reticulum which is cleaved by microsomal enzymes to produce proinsulin [6]. In pancreatic $\beta$-cells, proinsulin is transmitted in vesicles from rough endoplasmic reticulum to golgi apparatus and packaged into clathrin-coated secretory granules, where it is processed by a cascade of proconvertases and carboxypeptidases, resulting in the portal circulation of equimolar amounts of $\mathrm{C}$-peptide and insulin [7]. The plasma and urine concentration of $\mathrm{C}$-peptide has been widely used as a means of measuring $\beta$-cell secretory activity. The reason for this approach depends on the fact that the liver is the major site of insulin metabolism, variably extracting $50 \%$ of insulin delivered to it [8]. C-peptide does not experience significant hepatic extraction. Thus, it has been suggested that peripheral C-peptide levels more precisely reflect pancreatic insulin secretion than peripheral insulin [9]. It is necessary that C-peptide levels to be interpreted with caution in renal failure, as half of $\mathrm{C}$-peptide produced is removed by the kidneys, the majority of which is degraded via peritubular uptake with approximately $5 \%$ of total C-peptide produced excreted unchanged in the urine [10]. In recent years, clinical and experimental information have revealed several insulin-like effects, other than a decrease in blood glucose levels, which may be ascribed specially to C-peptide [11]. These effects propose the possibility of a clinically applicable role for C-peptide therapy to potentially alleviate or reverse the secondary microvascular complications of diabetes. Indeed, diabetic nephropathy, neuropathy and possibly retinopathy have enhanced in patients treated with C-peptide [12]. C-peptide's beneficial role on microvascular secondary complications has been shown to be nitric oxide (NO) mediated. The vascular microangiopathy that occurs in patients with diabetes may be due to decreased availability of nitric oxide (NO), which can be caused by impaired nitric oxide synthesis or to increased nitric oxide inactivation [13]. Certainly, C-peptide stimulates endothelial nitric oxide (eNOS) activity in a concentration-dependent manner [14]. The purpose of this study is to assess the level of fasting C-peptide as a predictor of $\beta$-Cell Function in Sudanese patients with T2DM. 


\section{Subjects and Methods}

\subsection{Study Design and Study Population}

Ethical approval was received from the Ethics Committee of Faculty of Medicine, University of Gezira following the Ethical Principles for Medical Research Involving Human Subjects. Personal consent was obtained from all study subjects prior to participation in the study. A hundred patients who were attending the Diabetic patients care Centre at Gezira State during May to July 2015 were recruited. Inclusion criteria were Sudanese T2DM patients with age range between 40 - 55 years. Patients with kidney disease, liver disease, cardiovascular disease, gestational diabetes were excluded from the study. A questionnaire was used to collect personal data and information about age, duration of diabetes, family history and laboratory investigations. Blood samples were collected after an overnight fasting ( 8 - 12 hours). Five $\mathrm{ml}$ of venous blood sample were collected to determine the levels of C-peptide, $\mathrm{HbAlc}$ and glucose. The serum was separated by centrifugation $1000 \mathrm{rpm}$ for 20 minutes and stored at $-20^{\circ} \mathrm{C}$ till estimation of C-peptide.

\subsection{Methods}

Blood glucose levels were estimated by glucose oxidase/peroxidase method using Biosystems analyzer A25, Spain. HbAlc was measured by Boronic Acid Affinity method using LabonaCheck ${ }^{\mathrm{TM}}$. HbAlc Analyzer, Korea. HbA1c levels were calculated in National Glycohemoglobin Standardization Program value. C-peptide values were measured by Cobas, Hitachi, Japan.

\subsection{Calculation of HOMA-B and HOMA-IR}

Homeostasis model assessment (HOMA) applied to assess $\beta$-cell function, however insulin therapy interferes with the endogenous insulin secretion in type 2 diabetics, therefore HOMA is unsuitable for insulin-treated patients. The Homeostasis model assessment beta-cell function was calculated using the equation, beta-cell function (HOMA-B) $=0.27 \times \mathrm{FCP} /($ FPG-3.5) [15]. The Homeostasis model assessment insulin resistance was calculated using the equation: HOMA-IR $(C P)=1.5$ + fasting blood glucose $\times$ fasting C-peptide/2800 [16].

\subsection{Statistical Analysis}

The obtained data of the study subjects presented as means \pm standard error of mean (SEM). A statistical analysis performed by using statistical package of social sciences SPSS version 20. Bivariate correlation analysis and simple linear regression analysis was used to correlate between the variables. Analysis of variance (ANOVA) was conducted to compare the difference between the C-peptide subgroups. $p$ value $\leq 0.05$ was considered as statistically significant.

\section{Results}

As Table 1 shows, 35 (35\%) were males and 65 (65\%) were females with mean 
age of $50.29 \pm 0.456$ years, and body mass index was $26.54 \pm 0.437$. The duration since the diagnosis of the disease was $5.85 \pm 0.343$ years, and $31 \%$ of the patients were having family history of T2DM. When simple bivariate correlation analysis was performed (Table 2), C-peptide was significantly and positively correlated with HOMA-B and HOMA-IR ( $\mathrm{r}=0.543, p<0.0001, \mathrm{r}=0.789, p<0.0001$ ) respectively. FBG also showed significant negative correlation with HOMA-B ( $\mathrm{r}=$ $-0.664, p<0.0001)$ but was positively and significantly correlated with HOMA-IR $(\mathrm{r}=0.546, p<0.0001)$. FBG showed significant positive correlation with $\mathrm{HbA1c}(\mathrm{r}=0.522, p<0.0001)$, HbA1c was negatively and significantly correlated with HOMA-B $(\mathrm{r}=-0.433, p<0.0001)$. These results suggest that $\mathrm{C}$-peptide levels predict insulin secretion from pancreatic $\beta$-cells and increase in $\mathrm{C}$-peptide levels might predict insulin resistance in patients with high levels of C-peptide. On the other hand, increase in FBG levels is associated in decreased $\beta$-cell function, but the positive correlation of FBG with HOMA-IR shows decreased insulin sensitivity and insulin resistance. The patients were classified into three categories (Table 3 ) according to the levels of fasting C-peptide, low level (less than $1.1 \mathrm{ng} / \mathrm{mL}$ ), normal level (1.1 - $4.4 \mathrm{ng} / \mathrm{mL}$ ), and high level (more than $4.4 \mathrm{ng} / \mathrm{mL}$ ) comparing the HOMA-B, HOMA-IR, FBG, and HbA1c. HOMA-B, and HOMA-IR were significantly elevated in patients with increased C-peptide levels, but HbA1c was significantly increased in patients with low C-peptide levels, in contrast no difference of FBG in C-peptide categories was found, but mean concentration of FBG was high in lower C-peptide patients. Patients with low $\mathrm{C}$-peptide level were having normal BMI while those with normal and increased C-peptide levels were having increased BMI. These results show the association between increased BMI and insulin resistance in patients with normal and high C-peptide levels; patients with lower levels of C-peptide have increased FBG and HbA1c, this also confirms decreased $\beta$-cell function in patients with low C-peptide levels. When linear regression analysis was performed (Table 4),

Table 1. Profile of the study group.

\begin{tabular}{cc}
\hline Male/female (35/65) & mean \pm SEM \\
Age (years) & $50.29 \pm 0.456$ \\
Weight (Kg) & $70.6 \pm 1.175$ \\
BMI (Kg/m $\left.{ }^{2}\right)$ & $26.54 \pm 0.437$ \\
Duration of the diabetes (years) & $5.58 \pm 0.343$ \\
Family history (yes/no) (31/69) & \\
C-peptide (ng/mL - pmol/1) & \\
HOMA-B & $2.976 \pm 0.141-992.157 \pm 47.283$ \\
HOMA-IR & $52.62 \pm 4.032$ \\
FBG (mg/dL - mmol/l) & $5.203 \pm 0.222$ \\
HbAlc (\%) & $188.03 \pm 6.633-10.446 \pm 0.369$ \\
\hline
\end{tabular}


Table 2. Correlation analysis of C-peptide, HOMA-B, HOMA-IR, FBG and HbA1c.

\begin{tabular}{ccccccc}
\hline & & C-peptide & HOMA-B & HOMA-IR & FBG & HbAlc \\
\hline C-peptide & $\mathrm{r}$ & 1.000 & & & & \\
& $p$ & & & & & \\
HOMA-B & $\mathrm{r}$ & $\mathbf{0 . 5 4 3}$ & 1.000 & & & \\
& $p$ & $<0.0001$ & & & & \\
HOMA-IR & $\mathrm{r}$ & $\mathbf{0 . 7 8 9}$ & 0.006 & 1.000 & & \\
& $p$ & $<0.0001$ & 0.952 & & & \\
FBG & $\mathrm{r}$ & 0.002 & -0.664 & $\mathbf{0 . 5 6 4}$ & 1.000 & \\
& $p$ & 0.986 & $<0.0001$ & $<0.0001$ & & \\
HbA1c & $\mathrm{r}$ & -0.193 & -0.433 & 0.098 & 0.522 & 1.000 \\
& $p$ & 0.054 & $<0.0001$ & 0.330 & $<0.0001$ & \\
\hline
\end{tabular}

Table 3. Comparison of HOMA-B, HOMA-IR, FBG, and HbA1c in C-peptide categories (mean \pm SEM).

\begin{tabular}{ccccc}
\hline Parameters & Low CP $(\mathbf{n}=\mathbf{3})$ & Normal CP $(\mathbf{n}=\mathbf{8 8})$ & High CP $(\mathbf{n}=9)$ & $P$ value \\
\hline HOMA-B & $8.98 \pm 3.17$ & $50.52 \pm 3.79$ & $87.65 \pm 21.59$ & $\mathbf{0 . 0 0 8}$ \\
HOMA-IR & $3.14 \pm 0.24$ & $4.81 \pm 0.16$ & $9.74 \pm 1.01$ & $<0.001$ \\
FBG (mg/dl) & $270.67 \pm 54.47$ & $183.13 \pm 6.85$ & $208.44 \pm 20.89$ & 0.072 \\
HbAlc & $7.90 \pm 1.159$ & $6.36 \pm 0.13$ & $5.7 \pm 0.36$ & $\mathbf{0 . 0 2 2}$ \\
BMI & $24.96 \pm 3.37$ & $26.43 \pm 0.44$ & $28.13 \pm 2.07$ & 0.449 \\
\hline
\end{tabular}

Table 4. Linear regression analysis of FBG levels with the selected parameters.

\begin{tabular}{cccc}
\hline Dependent variable & Independent variables & Unstandardized coefficients B & $P$ value \\
\hline C-peptide & -48.959 & $<0.0001$ \\
HOMA-B & -0.008 & 0.956 \\
FBG & HOMA-IR & 41.052 & $<0.0001$ \\
& HbAlc & 10.274 & $<0.0001$ \\
& BMI & -0.666 & 0.270 \\
& Duration of diabetes & -0.357 & 0.629 \\
\hline
\end{tabular}

considering fasting blood glucose as dependent factor, C-peptide and HOMA-IR were the major predictors of FBG $(p<0.0001)$, these results reflect the decrease in C-peptide is associated with increase in fasting glucose level demonstrating insulin secretion capacity and $\beta$-cell dysfunction. The significant association between FBG and HOMA-IR predicts the insulin insensitivity and insulin resistance in patients with high levels of C-peptide. Further, no significant relationship between HOMA-B, BMI and duration of diabetes with FBG was documented.

\section{Discussion}

In the current study, we assessed $\beta$-cell function using various indices of $\beta$-cell 
function such as C-peptide, homeostasis $\beta$-cell function (HOMA-B), and glycemic indices including fasting blood glucose and glycated hemoglobin (HbA1c). In our study, we used HOMA-B formula to evaluate the islet $\beta$-cell function. The results showed positive correlation between HOMA-B and $\mathrm{C}$-peptide fluctuations. Our results were in accordance with the results of $\mathrm{Hu}$ and Li., 2014 who found a positive correlation between HOMA-B indices and postprandial C-peptide levels and stated that the fluctuation levels of plasma C-peptide could assess the residual $\beta$-cell function and suggested that HOMA formula was practical on evaluation of the $\beta$-cell function in T2DM [15]. In a longitudinal study, it was suggested that C-peptide is more determinant than insulin in the development of diabetes mellitus [17]. A study conducted by Funakoshi et al., 2011, proposed that glucose toxicity might deteriorate insulin secretion, and patients with T2DM will require insulin therapy for the control of hyperglycemia [18]. This insulin therapy includes various treatment schedules: basal insulin-supported oral therapy (BOT) or multiple daily insulin injection (MDI) [19]. Recently, serum C-peptide is recommended for identifying MDI requiring patients [20]. In our results, an inverse relationship between fasting blood glucose levels with HOMA-B shows the effect of increased blood glucose levels and its correlation with pancreatic $\beta$-cell dysfunction and the insulin secretion capacity. Factors in deteriorating pancreatic $\beta$-cell function during diabetic exposure including hyperglycemia, hyperlipidemia, cytokines secreted by adipocytes, immune response, and medication have been proposed based mainly on in vitro studies, but clinical evidence of the influence of these factors on $\beta$-cell deterioration remains to be elucidated [21]. The inverse association between $\mathrm{HbA1c}$ and $\beta$-cell function suggests the role of hyperglycemia in the insulin secretory defect. Our results revealed an inverse correlation between HOMA-B and the level of HbAlc. This was in agreement with the results of Nakayama et al., 2015, who found in their cross-sectional data an inverse association between the levels of HbA1c and insulin secretory capacity [22]. Besides, C-peptide is equimolarly released with insulin, not as insulin that rapidly degraded in the liver, it has a 10-fold longer half-life. Therefore, C-peptide considered a more reliable marker of pancreatic insulin secretion than insulin (Lee, et al., 2011). In simple correlation analysis, $\mathrm{HbAlc}$ was negatively correlated with fasting C-peptide levels. This finding is in line with the results of Funakoshi et al [18], who stated the decline in the $\beta$-cell function in type 2 diabetes was most likely caused by the extensive loss of $\beta$-cell mass. Further, it has been elucidated that in chronic hyperglycemia causes $\beta$-cell dysfunction thru reduced Pancreatic duodenal homeobox 1 (Pdx1) expression. Inhibition of insulin/insulin-like growth factor signaling followed by reduced Pdx1 expression is a common pathway induced by the majority of the mechanisms in apoptotic $\beta$-cells [23].

According to the linear regression analysis $\mathrm{HbAlc}$, C-peptide and HOMA-IR were the major predictors for increased levels of fasting blood glucose. Every unit increase in $\mathrm{HbAlc}$ corresponds to $10.27 \mathrm{mg} / \mathrm{dl}$ increase in FBG; inversely, 
an increase in C-peptide is associated with a decrease in FBG of $48.96 \mathrm{mg} / \mathrm{dl}$, while the HOMA-IR coincides with increase in FBG of $41.052 \mathrm{mg} / \mathrm{dl}$. Serum fasting C-peptide level is useful for classifying diabetes: if the C-peptide level was $<0.6 \mathrm{ng} / \mathrm{mL}$ at diagnosis, T2DM could be excluded; if C-peptide level was $>3.0$ $\mathrm{ng} / \mathrm{mL}$, a T1DM diagnosis is unlikely [24]. In contrast, our results showed no association between HOMA-B, BMI and duration of diabetes with fasting blood glucose levels. In Asian populations, inadequate $\beta$-cell response to increasing insulin resistance is considered as the cause of loss of glycemic control and increased risk of diabetes, even with relatively little weight gain [25]. Although HOMA-B model is performed in large clinical and epidemiological studies, it is not suitable for some diabetic patients because of hyperglycemic state or insulin use. In addition, a recent study measuring $\beta$-cell area in humans showed that there was no relationship between HOMA-B and $\beta$-cell area [26]. Therefore, it is important to identify accurate markers for setting up the staging and determining the severity of T2DMs, as well as an index to determine a treatment regimen for diabetes.

\section{Conclusions and Limitations}

Fasting C-peptide is a useful marker of pancreatic $\beta$-cell function, and its circulating levels could be used to evaluate insulin secretion and insulin resistance. Moreover, HOMA-IR is an effective index to achieve glycemic control.

Our study had some limitations; the small number of patients and the limited number of the measured parameters can be considered in the future.

\section{Acknowledgements}

The authors would like to acknowledge all the patients who participated in this study and medical staff of Diabetic Patients Care Centre.

\section{Conflicts of Interest}

The authors declare no conflicts of interest regarding the publication of this paper.

\section{References}

[1] Nordquist, L., Palm, F. and Andresen, B.T. (2008) Renal and Vascular Benefits of C-Peptide: Molecular Mechanisms of C-Peptide Action. Biologics, 2, 441-452. https://doi.org/10.2147/BTT.S3221

[2] Bloomgarden, Z. (2016) Questioning Glucose Measurements Used in the International Diabetes Federation (Idf) Atlas. Journal of Diabetes, 8, 746-747. https://doi.org/10.1111/1753-0407.12453

[3] Zheng, Y., Ley, S.H. and Hu, F.B. (2018) Global Aetiology and Epidemiology of Type 2 Diabetes Mellitus and Its Complications. Nature Reviews Endocrinology, 14, 88-98. https://doi.org/10.1038/nrendo.2017.151

[4] Ashcroft, F.M. and Rorsman, P. (2012) Diabetes Mellitus and the Beta Cell: The Last Ten Years. Cell, 148, 1160-1171. https://doi.org/10.1016/j.cell.2012.02.010 
[5] American Diabetes Association (2014) Diagnosis and Classification of Diabetes Mellitus. Diabetes Care, 37, S81-S90. https://doi.org/10.2337/dc14-S081

[6] Oran, P.E., Jarvis, J.W., Borges, C.R. and Nelson, R.W. (2010) C-Peptide Microheterogeneity in Type 2 Diabetes Populations. Proteomics-Clinical Applications, 14, 106-111. https://doi.org/10.1002/prca.200800249

[7] Ghorbani, A. and Shafiee-Nick, R. (2015) Pathological Consequences of C-Peptide Deficiency in Insulin-Dependent Diabetes Mellitus. World Journal of Diabetes, 6 , 145-150. https://doi.org/10.4239/wjd.v6.i1.145

[8] Polonsky, K.S., Licinio-Paixao, J., Given, B.D., Pugh, W., Rue, P., Galloway, J., Karrison, T. and Frank, B. (1986) Use of Biosynthetic Human C-Peptide in the Measurement of Insulin Secretion Rates in Normal Volunteers and Type I Diabetic Patients. Journal of Clinical Investigation, 77, 98-105.

https://doi.org/10.1172/JCI112308

[9] Wildova, E., Kraml, P., Potockova, J., Dlouhy, P. and Andel, M. (2017) The Assessment of the Serum C-Peptide and Plasma Glucose Levels by Orally Administered Whey Proteins in Type 2 Diabetes Mellitus. Physiological Research, 66, 993-999.

[10] Jones, A.G. and Hattersley, A.T. (2013) The Clinical Utility of C-Peptide Measurement in the Care of Patients with Diabetes. Diabetic Medicine, 30, 803-817.

https://doi.org/10.1111/dme.12159

[11] Marques, R.G., Fontaine, M.J. and Rogers, J. (2004) C-Peptide: Much More Than a Byproduct of Insulin Biosynthesis. Pancreas, 29, 231-238.

https://doi.org/10.1097/00006676-200410000-00009

[12] Johansson, B.L, Kernell, A., Sjöberg, S. and Wahren, J. (1993) Influence of Combined C-Peptide and Insulin Administration on Renal Function and Metabolic Control in Diabetes Type 1. The Journal of Clinical Endocrinology \& Metabolism, 77, 976-981.

[13] Zanchi, A., Moczulski, D.K., Hanna, L.S., Wantman, M., Warram, J.H. and Krolewski, A.S. (2000) Risk of Advanced Diabetic Nephropathy in Type 1 Diabetes Is Associated with Endothelial Nitric Oxide Synthase Gene Polymorphism. Kidney International, 57, 405-413. https://doi.org/10.1046/j.1523-1755.2000.00860.x

[14] Cotter, M.A., Ekberg, K., Wahren, J. and Cameron, N.E. (2003) Effects of Proinsulin C-Peptide in Experimental Diabetic Neuropathy: Vascular Actions and Modulation by Nitric Oxide Synthase Inhibition. Diabetes, 52, 1812-1817. https://doi.org/10.2337/diabetes.52.7.1812

[15] Hu, L. and Li, D.H. (2014) Relationship between Modified Homeostasis Model Assessment/Correlative Serum Factors and Diabetic Retinopathy among Type 2 Diabetics with Insulin Therapy in Guangzhou, China. International Journal of Ophthalmology, 7, 463-468.

[16] Li, X., Zhou, G., Qi, H.Y., Chen, X.Y. and Huang, G. (2004) [Replacement of Insulin by Fasting C-Peptide in Modified Homeostasis Model Assessment to Evaluate Insulin Resistance and Islet Beta Cell Function. Journal of Central South University. Medical Sciences, 29, 419-423.

[17] Jung, H.S. (2016) Prediction of Diabetes Using Serum C-Peptide. Endocrinology and Metabolism, 31, 275-276. https://doi.org/10.3803/EnM.2016.31.2.275

[18] Funakoshi, S., Fujimoto, S., Hamasaki, A., Fujiwara, H., Fujita, Y., Ikeda, K., Takahara, S., Seino, Y. and Inagaki, N. (2011) Analysis of Factors Influencing Postprandial C-Peptide Levels in Japanese Patients with Type 2 Diabetes: Comparison with C-Peptide Levels after Glucagon Load. Journal of Diabetes Investigation, 2, 429-434. https://doi.org/10.1111/j.2040-1124.2011.00126.x 
[19] Shimizu, T., Nathan, D.M., Buse, J.B., Davidson, M.B., Ferrannini, E., Holman, R.R., Sherwin, R. and Zinman, B. (2012) Medical Management of Hyperglycemia in Type 2 Diabetes: A Consensus Algorithm for the Initiation and Adjustment of Therapy. A Consensus Statement of the American Diabetes Association and the European Association for the Study of Diabetes. Nippon Rinsho, 70, 591-601.

[20] Fujiwara, D., Takahashi, K., Suzuki, T., Shii, M., Nakashima, Y., Takekawa, S., Yoshida, A. and Matsuoka, T. (2013) Postprandial Serum C-Peptide Value Is the Optimal Index to Identify Patients with Non-Obese Type 2 Diabetes Who Require Multiple Daily Insulin Injection: Analysis of C-Peptide Values before and after Short-Term Intensive Insulin Therapy. Journal of Diabetes Investigation, 4, 618-625. https://doi.org/10.1111/jdi.12103

[21] Funakoshi, S., Fujimoto, S., Hamasaki, A., Fujiwara, H., Fujita, Y., Ikeda, K., Hamamoto, Y., Hosokawa, M., Seino, Y. and Inagaki, N. (2008) Analysis of Factors Influencing Pancreatic Beta-Cell Function in Japanese Patients with Type 2 Diabetes: Association with Body Mass Index and Duration of Diabetic Exposure. Diabetes Research and Clinical Practice, 82, 353-358. https://doi.org/10.1016/j.diabres.2008.09.010

[22] Nakayama, H., Kato, T., Nakayama, S., Kaku, H., Muraishi, K., Tokubuchi, I., Hara, K., Kato, T., Wada, N., Tsuruta, M., Ohki, T., Tanaka, K., Mitsuzaki, K., Tajiri, Y. and Yamada, K. (2015) Cross-Sectional and Longitudinal Analyses of Factors Contributing to the Progressive Loss of the Beta-Cell Function in Type 2 Diabetes. Internal Medicine, 54, 1971-1976. https://doi.org/10.2169/internalmedicine.54.4351

[23] Fujimoto, K. and Polonsky, K.S. (2009) Pdx1 and Other Factors That Regulate Pancreatic Beta-Cell Survival. Diabetes, Obesity \& Metabolism, 11, 30-37. https://doi.org/10.1111/j.1463-1326.2009.01121.x

[24] Cho, M.J., Kim, M.S., Kim, C.J., Kim, E.Y., Kim, J.D., Kim, E.Y. and Lee, D.Y. (2014) Fasting Serum C-Peptide Is Useful for Initial Classification of Diabetes Mellitus in Children and Adolescents. Annals of Pediatric Endocrinology \& Metabolism, 19, 80-85. https://doi.org/10.6065/apem.2014.19.2.80

[25] Lee, E.Y., Hwang, S., Lee, S.H., Lee, Y.H., Choi, A.R., Lee, Y., Lee, B.W., Kang, E.S., Ahn, C.W., Cha, B.S. and Lee, H.C. (2014) Postprandial C-Peptide to Glucose Ratio as a Predictor of Beta-Cell Function and Its Usefulness for Staged Management of Type 2 Diabetes. Journal of Diabetes Investigation, 5, 517-524. https://doi.org/10.1111/jdi.12187

[26] Meier, J.J., Menge, B.A., Breuer, T.G., Muller, C.A., Tannapfel, A., Uhl, W., Schmidt, W.E. and Schrader, H. (2009) Functional Assessment of Pancreatic Beta-Cell Area in Humans. Diabetes, 58, 1595-1603.

https://doi.org/10.2337/db08-1611 